\title{
A Destructive Leaf Spot and Blight Caused by Alternaria kareliniae sp. nov. on a Sand-Stabilizing Plant, Caspian Sea Karelinia
}

Biao Xu, Department of Plant Pathology, South China Agricultural University, Guangzhou, 510642, China; and Department of Biology, Tarim University, Aral, 843300, China; Jiage Song, Department of Biology, Tarim University, Aral, 843300, China; Pinggen Xi and Minhui Li, Department of Plant Pathology, South China Agricultural University; Tom Hsiang, School of Environmental Sciences, University of Guelph, Guelph, ON, N1G 2W1, Canada; and Zide Jiang, ${ }^{\dagger}$ Department of Plant Pathology, South China Agricultural University

\begin{abstract}
Leaf spots and stem lesions causing widespread mortality of Caspian Sea karelinia (Karelinia caspia) were observed in desert regions of Xinjiang Uyghur Autonomous Region, China. Fifteen samples were collected from five widely distributed counties of Tarim and Junggar Basins in 2016. The pathogen was identified using morphological observations and phylogenetic analyses based on combined partial sequences from seven genes (Alt a 1, ATPase, calmodulin, glyceraldehyde 3-phosphate dehydrogenase, internal transcribed spacer, RNA polymerase II, and translation elongation factor 1), and placed as a new species: Alternaria kareliniae sp. nov. in section Dianthicola. The fungus has a small conidium (24.3 to) 29.1 to 64.8

(to 75.8 ) by (9.3 to) 12.4 to 16.5 (to 21.7 ) $\mu \mathrm{m}$ with a long beak (130 to) 183.9 to 350.4 (to 378.2 ) $\mu \mathrm{m}$, as well as four to eight transverse septa, which differs significantly from other species of Alternaria section Dianthicola. On potato carrot agar, it grew significantly more slowly than others of this section. Pathogenicity tests showed that the fungus could infect leaves and stems of $K$. caspia and cause the same symptoms as those observed in the field. The fungus was reisolated from inoculated leaves and stems of the host. The disease in desert regions appears to be increasing, and it may have future negative implications for desert ecology in these areas. Future research should concentrate on elucidating the disease cycle and disease management alternatives.
\end{abstract}

The genus Alternaria Nees was established in 1816. Since then, more than 1,100 names have been published, and nearly 300 taxa have been accepted (Simmons 2007). Most Alternaria spp. are saprobes that are commonly found in soil or on decaying plant tissues (Thomma 2003). Some species are distributed worldwide, infecting a broad range of economically important crops, and are well known as destructive pathogens, such as Alternaria bataticola, A. porri, A. solani, and A. tomatophila (Abo-Elyousr et al. 2014; Lopes and Bioiteus 1994; Rotem 1994; Tymon et al. 2016). A few species have been intercepted as quarantine subjects in some countries (Sakoda et al. 2010). Accurate identification of plant-pathogenic fungi and the use of accepted names are essential for the development of effective biosecurity and trade policies as well as a prerequisite for risk assessment (Cai et al. 2011; Hyde et al. 2010). Alternaria spp. have been classified predominantly based upon their morphological characteristics, which include conidial morphology, catenulate spore patterns, and characteristics in pure culture. Recent molecular approaches based on multiple gene (e.g., Alt a 1, glyceraldehyde 3-phosphate dehydrogenase [GPDH], internal transcribed spacer [ITS], large subunit [LSU], RNA polymerase II [RPB2], translation elongation factor 1 [TEF1], and $\beta$-tubulin [TUB]) analyses have been widely used to determine the taxonomic status of species of Alternaria (Hong et al. 2005; Lawrence et al. 2012, 2013; Woudenberg et al. 2013). Furthermore, the use of plasma membrane ATPase and calmodulin, and comparisons of type or representative isolates, are recommended for accurate species identification within the genus Alternaria (Lawrence et al. 2013, 2016).

Caspian Sea karelinia (Karelinia caspia (Pall.) Less. (Asteraceae)) is an ecologically important plant species occurring across the desert ecosystems of Russia, Central Asia, and northwest China (Lin 1999). It exhibits both drought and salt tolerance, which allows it to play a role in reducing wind erosion and desertification (Vonlanthen et al. 2011). Previous studies with this plant have mainly concentrated

${ }^{\dagger}$ Corresponding author: Z. Jiang; E-mail: zdjiang@ @scau.edu.cn

Accepted for publication 25 August 2017.

() 2018 The American Phytopathological Society on ecology and stress tolerance (Wang et al. 2015; Zhang et al. 2014); however, diseases of this plant are poorly understood.

In late July 2014, a new and serious leaf spot disease was observed in the desert margin zone in northwest Tarim and southern Junggar Basins, Xinjiang Uyghur Autonomous Region of western China. In 2016, due to a significant increase in rainfall compared with previous years, the disease was more severe and caused an epidemic in some areas. Microscopic observations of infected Caspian Sea karelinia plants showed pathogen characteristics typical of the genus Alternaria. The objectives of this study were to (i) identify and characterize species of Alternaria associated with leaf spot and blight on Caspian Sea karelinia using molecular phylogenetic and morphological approaches, (ii) provide a detailed description of the leaf spot and blight on Caspian Sea karelinia caused by this pathogen, and (iii) assess the pathogenicity of these Alternaria isolates to Caspian Sea karelinia.

\section{Materials and Methods}

Disease investigation and sample collection. In September 2016, diseased Caspian Sea karelinia plants were surveyed and collected in five severely affected counties (Aksu, Aral, Karamay, Wujiaqu, and Xayar) in Tarim and Junggar Basins of Xinjiang Uyghur Autonomous Region (Fig. 1). These collection sites were distributed in an area covering over $1,000 \mathrm{~km}^{2}$, in areas with typically low annual rainfall ( $<200 \mathrm{~mm} /$ year). Each of the five severely affected plot areas was 10 by $10 \mathrm{~m}$, and all asymptomatic, symptomatic, and dead plants were surveyed. Plants were considered infected if they had a leaf spot or blight. With three samples per plot, 15 recently diseased leaves and stems showing typical leaf spot and blight were collected. Samples were transported to the laboratory and processed immediately or stored at $4{ }^{\circ} \mathrm{C}$ and processed within $24 \mathrm{~h}$ of collection.

Fungal isolations. Diseased leaves and stem tissues from necrotic margins were cut into 3- to 5-mm-long pieces and surface sterilized with $75 \%$ ethanol for 3 to $5 \mathrm{~s}$ and $3 \%$ sodium hypochlorite $(\mathrm{NaClO})$ for $2 \mathrm{~min}$. The samples were washed three times with sterile distilled water and blotted dry with sterilized filter paper. The sections were placed onto potato dextrose agar (PDA) supplemented with ampicillin at $100 \mu \mathrm{g} / \mathrm{ml}$ and incubated at $25^{\circ} \mathrm{C}$ in darkness for 10 days. Isolates were purified by single-spore culturing and subcultured onto malt extract agar (MEA), oatmeal agar (OA), potato carrot agar (PCA), and V8 juice agar (V8) and incubated at $25^{\circ} \mathrm{C}$ with a photoperiod of $12 \mathrm{~h}$ of light and $12 \mathrm{~h}$ of darkness to characterize fungal growth and morphology. 
Morphological studies. Morphological examinations were performed according to descriptions by Simmons (2007). Cultural and conidial morphology were examined after 10 days. Fifty mature conidia and conidiophores mounted in sterile water were randomly selected for size measurements under a compound light microscope (Olympus BX50). The specimens were deposited in the Mycological Herbarium of Tarim University, Aral, China and the Mycological Herbarium of South China Agricultural University, Guangzhou, China, and representative cultures are being maintained in the Culture Collection of Tarim University, Aral, China (CTU).
DNA extraction and polymerase chain reaction amplification. Mycelia were collected from PDA cultures 10 days after incubation and pulverized by the MP Fastprep-24 sample preparation system (MP Biomedicals). Genomic DNA was extracted using the E.Z.N.A.TM Fungal DNA kit (OMEGA Biotek), according to the manufacturer's instructions. The complete ITS region was amplified with the primers V9G (de Hoog and Gerrits van den Ende 1998) and ITS4 (White et al. 1990), the partial Alt a 1 region with Alt-for and Alt-rev (Hong et al. 2005), the partial TEF1 region with EF1-728F and EF1-986R (Carbone and Kohn 1999), the partial RPB2 region with RPB2-5F2

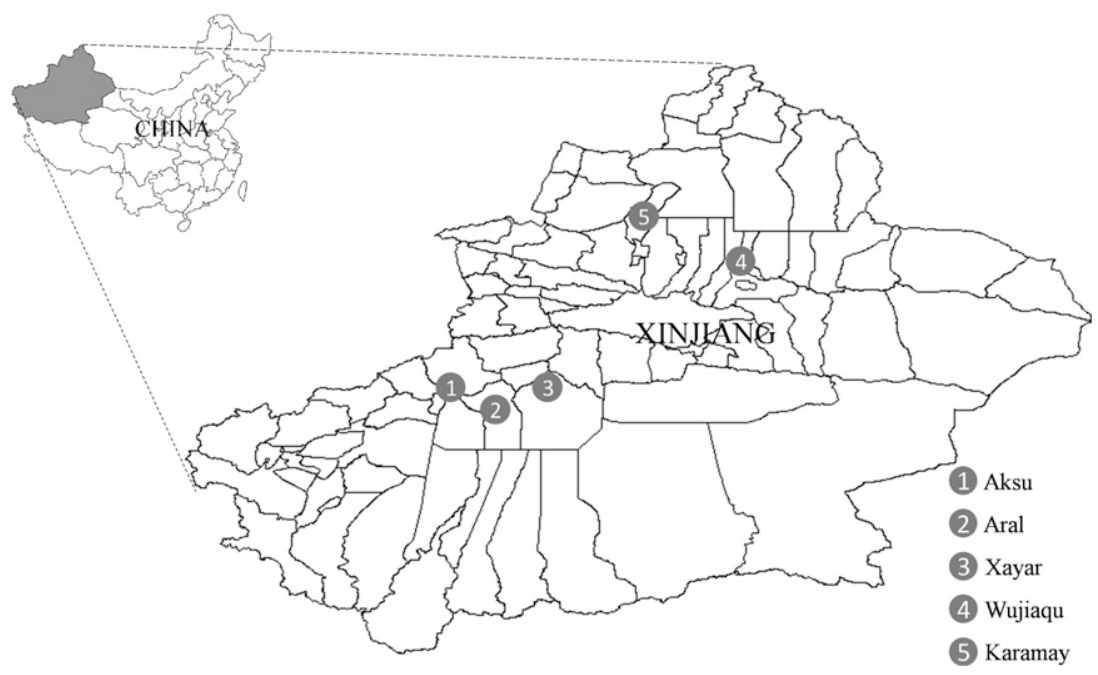

Fig. 1. Map of the Xinjiang Uyghur Autonomous Region showing the areas where Alternaria kareliniae was sampled in this study.

Table 1. Isolates used in this study and their GenBank accession numbers for seven genes ${ }^{\mathrm{a}}$

\begin{tabular}{|c|c|c|c|c|c|c|c|c|}
\hline \multirow[b]{2}{*}{ Sections, species names } & \multirow[b]{2}{*}{ Strains $^{\mathbf{b}}$} & \multicolumn{7}{|c|}{ GenBank accession numbers } \\
\hline & & ITS & GPDH & Alt a 1 & $R P B 2$ & Calmodulin & TEF1 & ATPase \\
\hline \multicolumn{9}{|l|}{$\overline{\text { Sect. Cheiranthus }}$} \\
\hline Alternaria cheiranthi & EGS 41-188; CBS 109384 & AF229457 & AY278802 & AY563290 & KC584387 & JQ646164 & KC584646 & JQ671830 \\
\hline A. indefessa & CBS 536.83T; EGS 30-195 & KC584234 & KC584159 & AY563323 & KC584458 & JQ646165 & KC584717 & JQ671831 \\
\hline \multicolumn{9}{|l|}{ Sect. Dianthicola } \\
\hline A. dianthicola & CBS 915.96; CBS 116491 & JQ693640 & KC584113 & - & KC584394 & JQ646144 & KC584653 & JQ671810 \\
\hline A. elegans & CBS 109159T; EGS 45.072 & NR_136040 & KC584114 & GQ180092 & KC584395 & - & KC584654 & - \\
\hline \multirow[t]{3}{*}{ A. kareliniae } & CTU C031T & KY945066 & KY945063 & KY945051 & KY945072 & KY945057 & KY945060 & KY945054 \\
\hline & CTU C033 & KY945067 & KY945064 & KY945052 & KY945073 & KY945058 & KY945061 & KY945055 \\
\hline & CTU C036 & KY945068 & KY945065 & KY945053 & KY945074 & KY945059 & KY945062 & KY945056 \\
\hline A. simsimi & CBS $115265 \mathrm{~T}$ & NR_136013 & KC584137 & - & KC584428 & - & KC584686 & - \\
\hline \multicolumn{9}{|l|}{ Sect. Pseudoulocladium } \\
\hline A. aspera & CBS 115269T & KC584242 & KC584166 & KF533899 & KC584474 & - & KC584734 & - \\
\hline A. chartarum & ATCC $18044 ;$ CBS $200.67 \mathrm{~T}$ & NR_130656 & AY278819 & AY563319 & KC584481 & JQ646162 & KC584741 & JQ671828 \\
\hline A. concatenata & CBS 120006; HSAUPXF 030035 & KC584246 & AY762950 & EU684149 & KC584480 & - & KC584740 & - \\
\hline A. septospora & CBS 109.38 & FJ266489 & FJ266500 & FJ266515 & KC584487 & JQ646163 & KC584747 & JQ671829 \\
\hline \multicolumn{9}{|l|}{ Sect. Ulocladioides } \\
\hline A. atra & ATCC 18040; CBS $195.67 T$ & AF229486 & KC584167 & - & KC584475 & JQ646167 & KC584735 & JQ671833 \\
\hline A. brassicae-pekinensis & CBS $121493 \mathrm{~T}$ & KC584244 & KC584170 & KF533892 & KC584478 & - & KC584738 & - \\
\hline A. cantlous & CBS 123007T; HSAUP 0572 & KC584245 & KC584171 & FJ041319 & KC584479 & - & KC584739 & - \\
\hline A. consortialis & CBS 104.31T; CBS 201-67 & KC584247 & KC584173 & FJ266509 & KC584482 & JQ646173 & KC584742 & JQ671839 \\
\hline A. cucurbitae & CBS 483.31; EGS 31-021 & FJ266483 & AY562418 & FJ008712 & KC584483 & JQ646170 & KC584743 & JQ671836 \\
\hline A. multiforme & CBS 102060T & FJ266486 & KC584174 & FJ266512 & KC584484 & JQ646171 & KC584744 & JQ671837 \\
\hline A. subcucurbitae & CBS $121491 \mathrm{~T}$ & KC584249 & EU855803 & EU855807 & KC584489 & - & KC584749 & - \\
\hline
\end{tabular}

Outgroup

Stemphylium vesicarium ATCC 1852; CNU 094002

AF229484 AY278821 AY563275

JQ646102

JF331624 JQ671768

a ITS = internal transcribed spacer, GPDH = glyceraldehyde 3-phosphate dehydrogenase, RPB2 = RNA polymerase II, TEF1 = translation elongation factor 1. Sequences obtained in this study are indicated in bold; - indicates sequence was not available.

${ }^{\mathrm{b}}$ ATCC $=$ American Type Culture Collection, Manassas, VA; CBS = culture collection of the Centraalbureau voor Schimmelcultures, Fungal Biodiversity Centre, Utrecht, The Netherlands; EGS = personal collection of Dr. E. G. Simmons; CTU: culture collection of Tarim University, Aral, China; HSAUP = Department of Plant Pathology, Shandong Agricultural University, Taian, China; CNU = culture collection of Chungnam National University, Daejeon, Korea; and T = ex-type strain. 
(Sung et al. 2007) and fRPB2-7cR (Liu et al. 1999), the partial calmodulin region with CALDF1 and CALDR1 (Lawrence et al. 2013), the partial ATPase region with ATPDF1 and ATPDR1 (Lawrence et al. 2013), and the partial GPDH region with gpd1 and gpd2 (Berbee et al. 1999). The polymerase chain reactions (PCR) were performed in a MyCycler Thermal Cycler (Bio-Rad) in a total volume of $25 \mu \mathrm{l}$ containing $2.5 \mu \mathrm{l}$ of 10× EasyTaq Buffer (Takara Biotech), $50 \mu \mathrm{M}$ $\mathrm{dNTP}, 0.1 \mu \mathrm{M}$ each primer, $0.75 \mathrm{U}$ of Taq DNA polymerase, and 1 to $10 \mathrm{ng}$ of genomic DNA. Conditions for PCR amplification consisted of an initial denaturation step of $4 \mathrm{~min}$ at $94^{\circ} \mathrm{C}$ followed by
35 cycles of $45 \mathrm{~s}$ at $94^{\circ} \mathrm{C}, 45 \mathrm{~s}$ at $56^{\circ} \mathrm{C}$, and $60 \mathrm{~s}$ at $72^{\circ} \mathrm{C}$ for ITS; 30 cycles of $60 \mathrm{~s}$ at $94^{\circ} \mathrm{C}, 60 \mathrm{~s}$ at $56^{\circ} \mathrm{C}$, and $45 \mathrm{~s}$ at $72^{\circ} \mathrm{C}$ for GAPDH and Alt a 1 ; and 30 cycles of $30 \mathrm{~s}$ at $94^{\circ} \mathrm{C}, 30 \mathrm{~s}$ at $59^{\circ} \mathrm{C}$, and $60 \mathrm{~s}$ at $72^{\circ} \mathrm{C}$ for ATPase, calmodulin, and TEF1. The partial $R P B 2$ gene was obtained by using a touchdown PCR protocol of 5 cycles of $45 \mathrm{~s}$ at $94^{\circ} \mathrm{C}, 45 \mathrm{~s}$ at $60^{\circ} \mathrm{C}$, and $2 \mathrm{~min}$ at $72^{\circ} \mathrm{C}$; followed by 5 cycles with a $58^{\circ} \mathrm{C}$ annealing temperature and 30 cycles with a $54^{\circ} \mathrm{C}$ annealing temperature, as described by Woudenberg et al. (2013); and a final elongation step of $10 \mathrm{~min}$ at $72^{\circ} \mathrm{C}$. The PCR products were sequenced bidirectionally at the Beijing Genomics Institute BGI, using the same primers
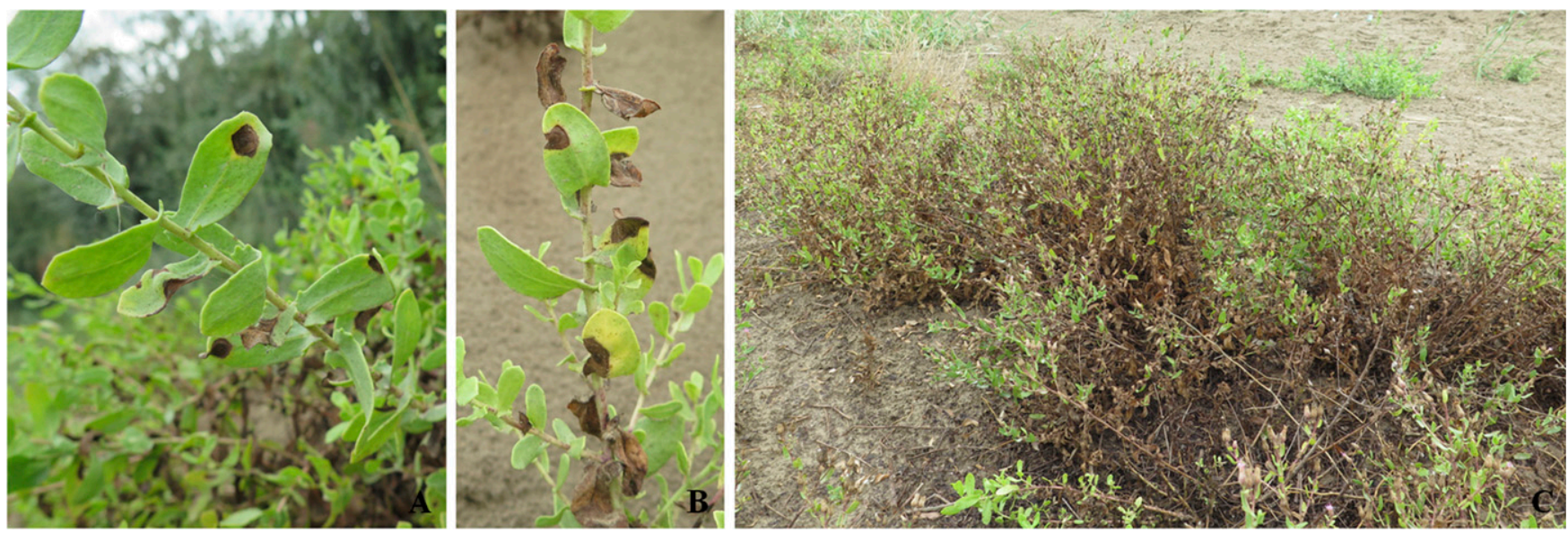

Fig. 2. Symptoms of infection by Alternaria kareliniae on Karelinia caspia in the field. A, Initial symptoms on leaves. B, Necrotic spots extending from leaves to stems. C, Whole plants withered.

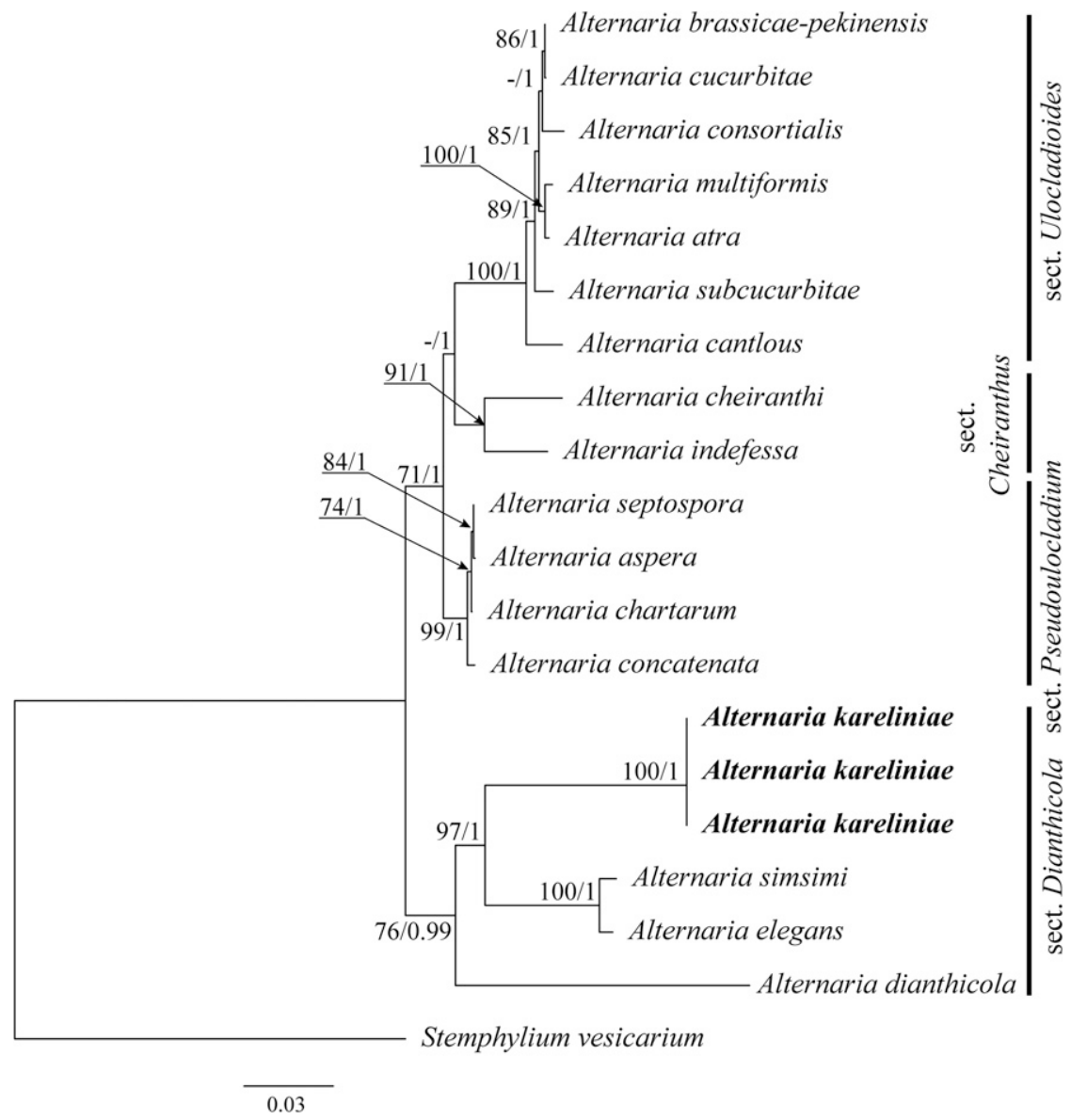

Fig. 3. Maximum-likelihood tree and Bayesian analyses inferred from analysis of combined ITS, GPDH, Alt a 1, RPB2, calmodulin, TEF1, and ATPase sequences of Alternaria isolates associated with genus Karelinia. Bootstrap values were calculated from 1,000 replications. RaxML bootstrap support values $>70$ (before the slash marks) and Bayesian posterior probabilities $>0.95$ (after the slash marks) are shown. The scale bar indicates the number of nucleotide substitutions. 
as those used in our PCR procedures. For each gene, consensus sequences were derived from both primer directions using MAFFT.

Phylogenetic analyses. Sequences of the isolates were aligned with published sequences of Alternaria spp. retrieved from GenBank (Table 1), using the online version of MAFFT, ver. 7.215 (Katoh and Standley 2013). Stemphylium vesicarium (Wallr.) E. G. Simmons (culture number ATCC 18521) was used as the outgroup taxon. When a gene sequence was not available for a particular isolate, the gene for that isolate was replaced by a consensus sequence for that gene constructed from the multiple alignment following Nei and Kumar (2000) and using SequenceMatrix, version 1.7.8 (Vaidya et al. 2011). The concatenated alignment was deposited in TreeBASE (https://www.treebase.org/) under accession S20906. Maximumlikelihood (ML) analyses were performed with RAxML 8.0.26 (Stamatakis 2014) by using RAxML GUI v. 1.31 (Silvestro and Michalak 2012) with a rapid bootstrap algorithm, the GTR GAMMAI model,

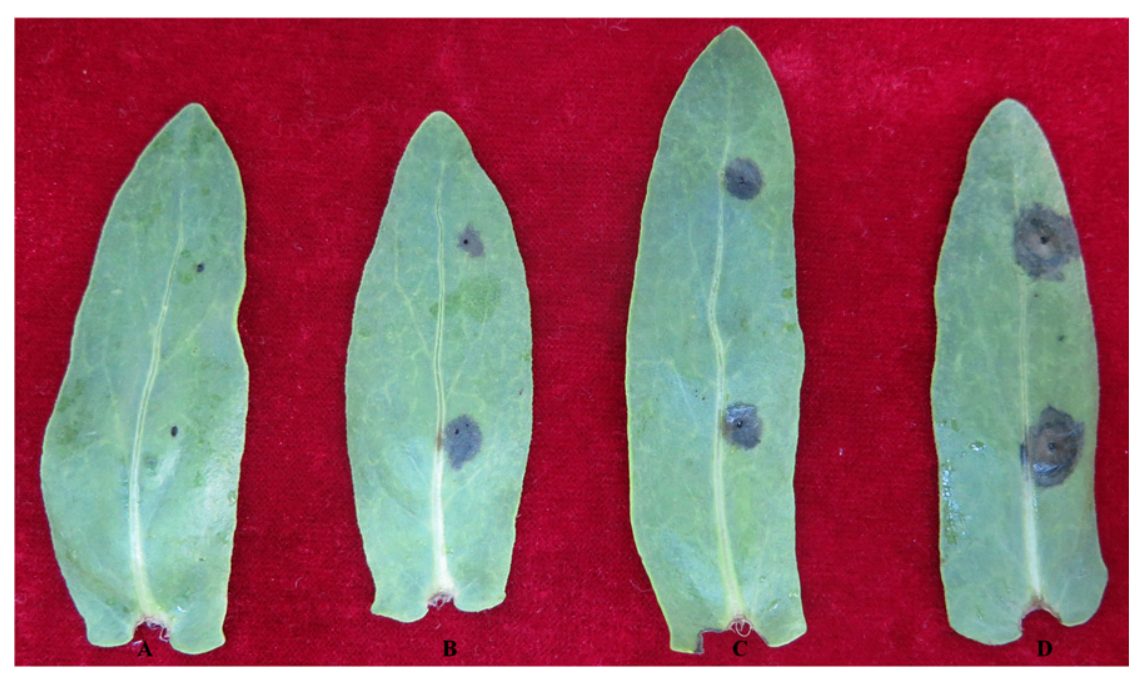

Fig. 4. Necrotic spots resulting from inoculation of Alternaria kareliniae onto Karelinia caspia leaves, and wound responses on the negative controls. A, Negative control inoculation sites showing wound and the absence of necrotic spot development and B, inoculation sites showing necrotic spots from isolate CTU C031T; C, isolate CTU C033; and D, isolate CTU C036.

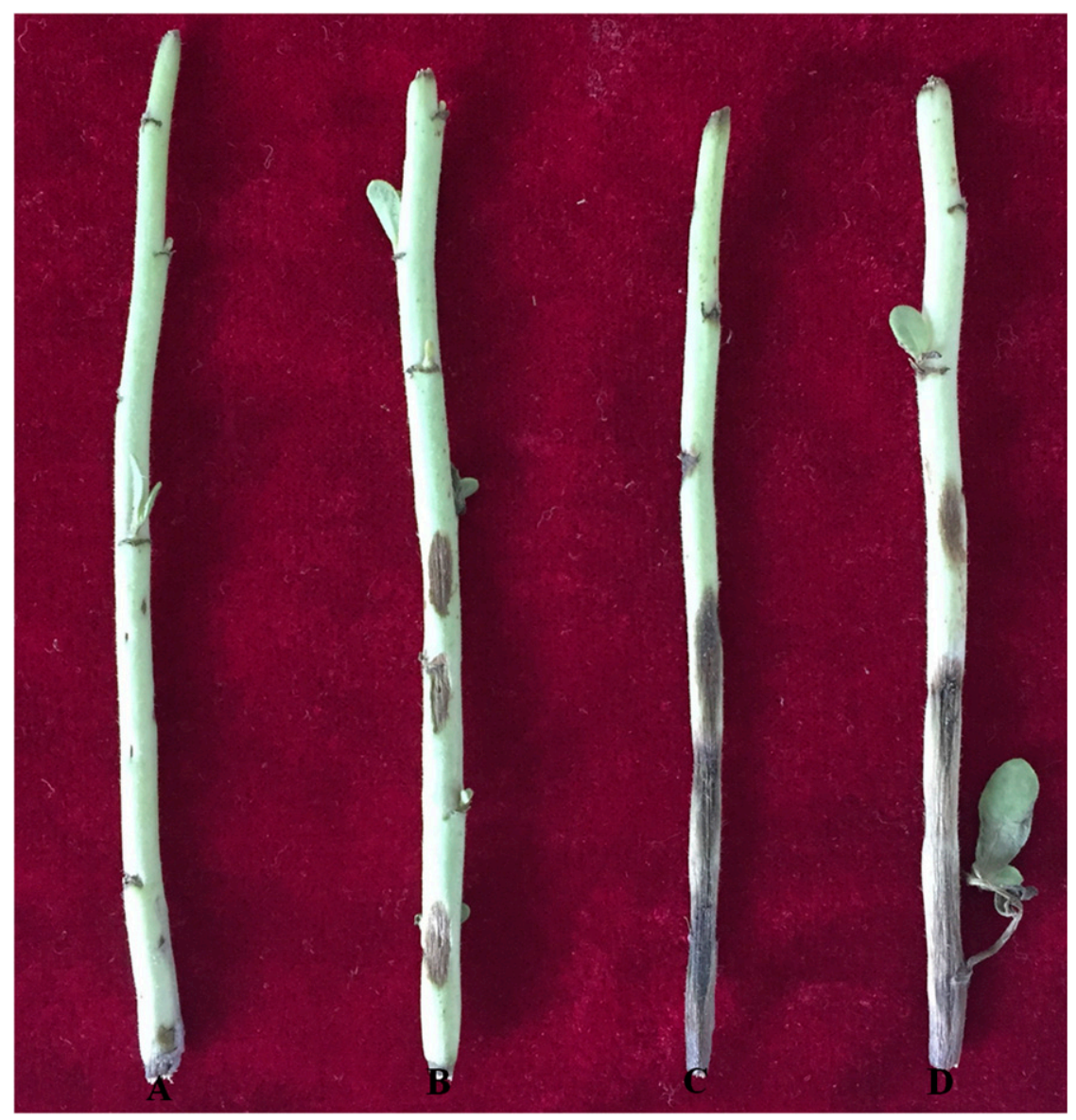

Fig. 5. Necrotic spots resulting from inoculation of Alternaria kareliniae onto Karelinia caspia stems, and wound responses on the negative controls. A, Negative control inoculation sites showing wound and the absence of necrotic spot development and B, inoculation sites showing necrotic spot from isolate CTU C031T; C, isolate CTU C033; and D, isolate CTU C036 
and 1,000 bootstrap replicates. Bayesian interference (BI) analyses were performed as described by Woudenberg et al. (2013) using MrBayes (Ronquist et al. 2012). The phylogenetic trees were checked and edited using FigTREE v1.4.0 (Rambaut 2007).

Pathogenicity tests. Two representative isolates (CTU C031T and CTU C033) from leaf spots and one (CTU C036) from stem lesions of Caspian Sea karelinia were used to inoculate wounded detached leaves and stems of healthy plants to test for pathogenicity, following Pryor and Michailides (2002). Spore suspensions of Alternaria
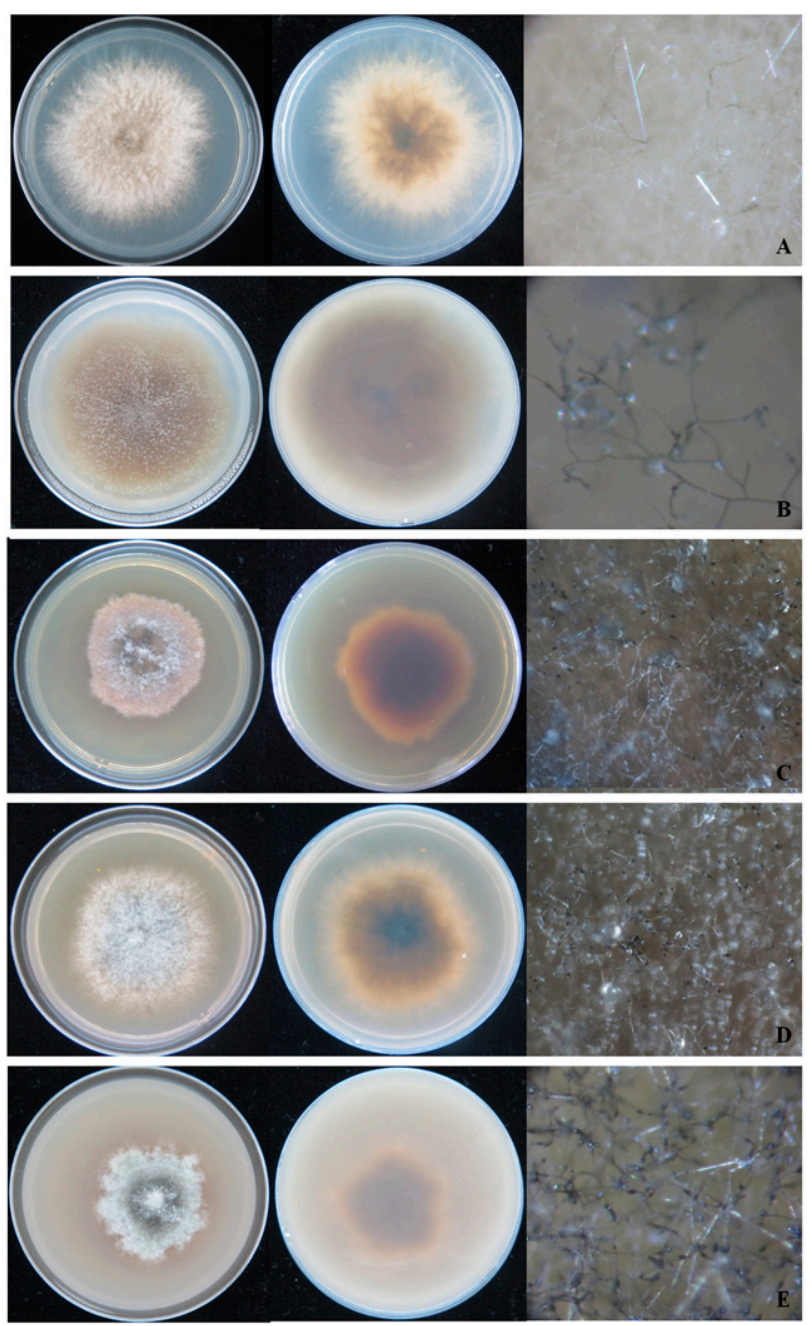

Fig. 6. Colony characteristics after 10 days of growth on A, potato dextrose agar; $\mathbf{B}$, oatmeal agar; C, malt extract agar; D, potato carrot agar; and E, V8 juice agar. isolates were prepared by flooding PDA cultures with sterile water and adjusting the collected suspension to $10^{5}$ spores $/ \mathrm{ml}$ using a hemacytometer. Tests were conducted on detached leaves and stems of Caspian Sea karelinia placed in Petri dishes on top of moistened autoclaved filter paper. Each inoculation site of leaf or stem was slightly wounded on the surface with a sterile dissecting needle prior to inoculation. A conidial suspension $\left(20 \mu \mathrm{l}\right.$ of $10^{5}$ spores $\left./ \mathrm{ml}\right)$ was placed on each wound site, with three replicates for each treatment. Control leaves and stems were mock inoculated with sterile water. Each test was incubated at $25 \pm 1{ }^{\circ} \mathrm{C}$ with 80 to $95 \%$ relative humidity under a photoperiod of $12 \mathrm{~h}$ of light and $12 \mathrm{~h}$ of darkness in a controlled-environment chamber.

\section{Results}

Disease investigation and fungal isolation. Symptoms of leaf spot and blight on $K$. caspia were found in many desert regions of the Tarim and Junggar Basins. Early symptoms appeared on the mature leaves in late July, in the form of numerous circular, small, dark-brown spots, with a dark halo on the leaf surface surrounded by chlorosis. The infection subsequently progressed to the younger leaves and caused severe necrotic lesions leading to defoliation (Fig. 2A and B). As the disease progressed, lesions occurred on the stems, which turned yellow. Heavy infection resulted in death of the plants (Fig. 2C). From the five regions examined, a 10-by-10-m plot was established in each region representing the highest levels of disease. Disease incidence in these plots ranged from 50 to $90 \%$ while mortality ranged from 40 to $70 \%$. Fifteen samples collected from the above plots were subjected to isolation, and all strains showed consistent morphology.

Phylogenetic analyses. Phylogenetic analyses were carried out on three representative strains (CTU C031T, CTU C033, and CTU C036) based on the sequences from seven genes: Alt a 1, ATPase, calmodulin, GPDH, ITS, RPB2 and TEF1 (GenBank accession numbers KY945051 to KY945077). PCR amplification and sequencing of each gene yielded product sizes for these three isolates of $473,1,195$, $722,580,491,865$, and $233 \mathrm{bp}$, respectively. The sequences were then concatenated for phylogenetic analyses. The three sequenced Alternaria isolates were compared with 17 other taxa (Table 1).

$\mathrm{ML}$ and $\mathrm{BI}$ analyses yielded the same tree topology, and a single tree with bootstrap support from ML and BPP (Bayesian posterior probabilities) from BI was generated (Fig. 3). The phylogenetic analysis showed that all isolates from Caspian Sea karelinia clustered together with statistical support of $100 \%$ BP (bootstrap proportions) and 1.00 BPP, and formed a strongly defined distinct lineage within Alternaria section (sect.) Dianthicola separated from A. simsimi, A. elegans, and A. dianthicola.

Pathogenicity tests. The three fungal isolates of $A$. kareliniae inoculated onto detached leaves and stems all gave symptoms of black leaf spot and stem necrosis after 3 to 5 days but no symptoms were observed in mock-inoculated control leaves and stems. Round necrotic spots appeared at the inoculation sites 1 to 2 days after
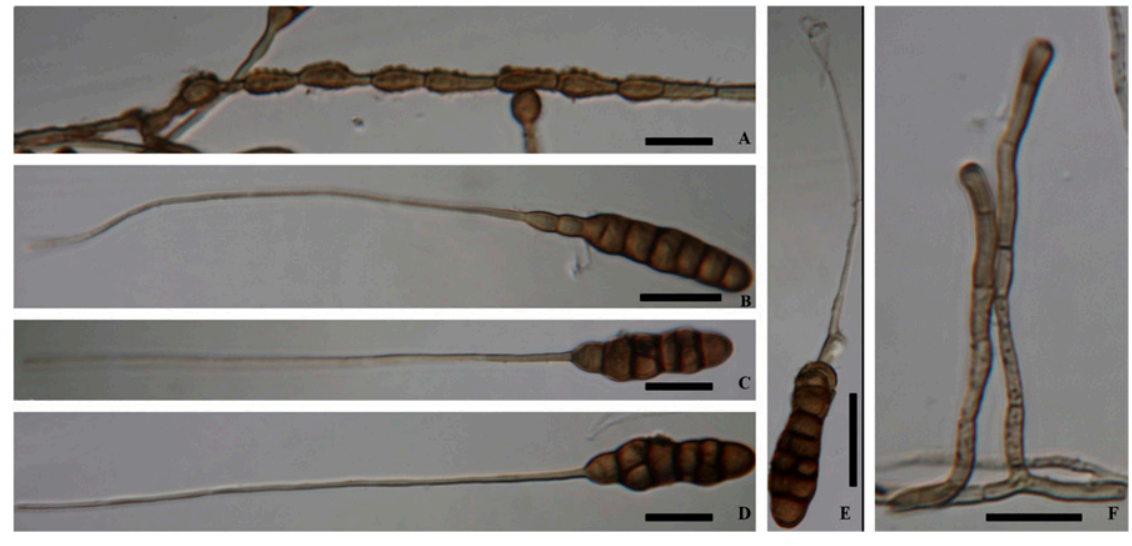

Fig. 7. Microscopic characteristics of Alternaria kareliniae. A, Chlamydospores; B, C, D, and E, conidia with long beaks; and F, conidiophores. Bar $=20 \mu \mathrm{m}$. 
inoculation, and spread along the entire leaves and stems within 5 days. The symptoms were similar to those observed in the field (Figs. 4 and 5). The fungus was easily reisolated from lesions of inoculated leaves and stems, and was identical to the original isolate based on colony morphology and molecular sequence.

Description of the pathogen. Based on the phylogenetic analyses of the combined seven-gene dataset, as well as morphological characteristics, the pathogen collected from $K$. caspia clearly represented a new species, which is described as follows:

Alternaria kareliniae B. Xu \& Z. D. Jiang sp. nov. (Figs. 6 and 7) MycoBank: MB 820927

After 10 days at $25^{\circ} \mathrm{C}$, colonies on PCA were consistent with PDA, white to pale gray, $34-48 \mathrm{~mm}$ diam. with medium olive zones on the reverse side. Colonies on MEA were similar to V8, gray to light olive, slightly orange-brown on the underside, 24-29 mm diam. On OA, colonies were gray, with sparse aerial mycelium, and 34-37 mm diam. (Fig. 6). Conidiophores arising singly, erect or curved, few branched, pale brown, smooth, round and scarred at the apex, (14.7-) 31.3-70.4 (-105.5) long $\mu \mathrm{m}, 3.1-5.8 \mu \mathrm{m}$ wide with 0-5 septa $(n=50)$. Conidia solitary, few in chains, conidia body (24.3-) 29.1$64.8(-75.8) \times(9.3-)$ 12.4-16.5 (-21.7) $\mu \mathrm{m}$, with 4-8 transverse septa and one to two longitudinal or oblique septa, constricted at the middle transverse septa, the beaks (130-) 183.9- 350.4 (-378.2) $\mu \mathrm{m}$ long, 2.1-3.3 $\mu \mathrm{m}$ wide with few septa, some cells bulging strongly in the lower part $(n=50)$ (Fig. 7).

Etymology. The specific epithet refers to the genus of the host plant (Karelinia caspia (Pall.) Less.)

Materials studied. In Xinjiang, China, Karamay County, 11 August 2016, (ex-type culture number CTU C031T) and Wujiaqu County, 26 August 2016 (culture number CTU C033) the isolates were derived from leaf spot of K. caspia; in Aral County, 15 September 2016, the isolates were derived from stem lesions (culture number CTU C036).

\section{Discussion}

This study resulted in the discovery of a previously undescribed Alternaria sp. on diseased $K$. caspia which is placed in sect.
Dianthicola. Combined morphological characteristics and phylogenetic analyses confirmed this fungus as a new taxon. The new species was described and named Alternaria kareliniae. Currently, Alternaria sect. Dianthicola contains three species, including $A$. simsimi, A. elegans, and A. dianthicola (Lawrence et al. 2016). A. dianthicola with a short beak is obviously different from other species in this section (Ellis and Ellis 1985), including the long-beaked A. kareliniae. However, there are only slight morphological differences between A. kareliniae, A. simsimi, and A. elegans. (Table 2). A. kareliniae has a slower growth rate under the same cultural conditions (PCA) than A. simsimi or A. elegans. In addition, A. kareliniae differs from A. simsimi by having a smaller conidial body and more septa than A. simsimi (conidial body 45 to 90 by 12 to $18 \mu \mathrm{m}$, with 7 to 10 transverse septa) (Simmons 2004). A. kareliniae sporulates as solitary or rarely chains of two conidia, while $A$. simsimi has chains of 2 to 4 conidia and conidiophores up to 75 to $200 \mu \mathrm{m}$ (Simmons 2000).

In previous work based on multigene sequence data analysis, phylogenetic lineages within Alternaria and allied genera were redelineated (Lawrence et al. 2013; Woudenberg et al. 2013). The results showed that the Alternaria clade contains 27 sections (internal clades) and eight monotypic lineages (Lawrence et al. 2016). The pathogen A. kareliniae belongs to sect. Dianthicola, which also consists of A. simsimi, A. elegans, and A. dianthicola. In our study, phylogenetic results from the combined dataset of the GPDH, $R P B 2$, and $T E F 1$ gene sequences produced topologies concordant with Woudenberg et al. (2013). In the combined dataset of the seven gene sequences, $A$. simsimi, A. elegans, and A. dianthicola and our three representative $A$. kareliniae isolates formed well-supported monophyletic entities (76\% BP, 0.99 BPP) (Fig. 3), and this topology was also concordant with Woudenberg et al. (2013).

In previous classifications, plant-pathogenic fungal species were often placed in association with a single host plant species or genus. In more recent classifications of Alternaria spp., phylogenetic analyses suggest that these specific host-pathogen associations within different plant families have occurred multiple times throughout the evolution of this taxon (Lawrence et al. 2016). Among Alternaria sect. Dianthicola, A. dianthicola, A. elegans, and A. simsimi are

Table 2. Morphological comparison of Alternaria kareliniae with A. dianthicola, A. elegans, and A. simsimi

\begin{tabular}{|c|c|c|c|c|c|}
\hline \multicolumn{2}{|c|}{ Characteristics } & \multirow[b]{2}{*}{ A. kareliniae } & \multirow[b]{2}{*}{ A. dianthicola } & \multirow[b]{2}{*}{ A. elegans } & \multirow[b]{2}{*}{ A. simsimi } \\
\hline$\overline{\text { Cultural }}$ & Colony & & & & \\
\hline \multirow{2}{*}{$\begin{array}{l}\text { Growth on } \\
\text { PCA }^{\mathrm{a}}\end{array}$} & Growth & Sparse & Abundant & Abundant & Abundant \\
\hline & Growth rate & $\begin{array}{l}34-48 \mathrm{~mm} \text { after } 10 \text { days } \\
4 \mathrm{~mm} / \text { day }\end{array}$ & $\begin{array}{l}35-40 \mathrm{~mm} \text { after } 5 \text { days } \\
7.5 \mathrm{~mm} / \text { day }\end{array}$ & Fast $^{\mathrm{b}}$ & $90 \mathrm{~mm}$ after 5 days $18 \mathrm{~mm} /$ day \\
\hline Sporulation & Shape & $\begin{array}{l}\text { Solitary or rare chains of two } \\
\text { conidia }\end{array}$ & Chains of $4-5$ conidia, & Chains of 2-4 conidia & $\begin{array}{l}\text { Chains of two or more conidia } \\
\text { abundant }\end{array}$ \\
\hline \multirow[t]{2}{*}{ Conidiophores } & Shape & $\begin{array}{l}\text { Simple or branched, a few } \\
\text { geniculate extensions }\end{array}$ & $\begin{array}{l}\text { Simple or branched, } \\
\text { Geniculate extensions }\end{array}$ & $\begin{array}{l}\text { Short branched, } \\
\text { Geniculate extensions }\end{array}$ & $\begin{array}{l}\text { Simple or branched, a few } \\
\text { Geniculate extensions }\end{array}$ \\
\hline & Size $(\mu \mathrm{m})$ & $\begin{array}{l}(14.7-) \text { 31.3-70.4 (-105.5) by } \\
3.1-5.8\end{array}$ & $5-150$ by $4-6$ & $75-200$ & Up to 80 by $3.0-5.0$ \\
\hline \multirow[t]{6}{*}{ Conidial body } & Shape & $\begin{array}{l}\text { Variable shape, diamond, } \\
\text { obclavate, ovoid or narrow } \\
\text { ellipsoid }\end{array}$ & $\begin{array}{l}\text { Obclavate to } \\
\text { cylindrical }\end{array}$ & Ovoid or ellipsoid & Narrowly ellipsoid \\
\hline & Size $(\mu \mathrm{m})$ & $\begin{array}{c}(24.3-) 29.1-64.8(-75.8) \text { by } \\
(-9.3) 12.4-16.5(-21.7)\end{array}$ & $55-130$ by $10-16$ & $30-69$ by $13-16$ & $45-90$ by $12-18$ \\
\hline & Transverse septa & $4-8$ & Up to 14 & $7-10$ & $7-10$ \\
\hline & Longitudinal septa & $1-2$ & $1-2$ & $1-2$ & $1-2$ \\
\hline & Color & $\begin{array}{l}\text { Brown with eusepta in darker } \\
\text { contrast }\end{array}$ & Pale olivaceous brown & $\begin{array}{l}\text { Moderate brown with } \\
\text { darker contrast }\end{array}$ & $\begin{array}{l}\text { Moderate brown with eusepta in } \\
\text { darker contrast }\end{array}$ \\
\hline & Ornamentation & Lack ornamentation & Lack ornamentation & Lack ornamentation & Lack ornamentation \\
\hline \multirow[t]{2}{*}{ Beak } & Shape & $\begin{array}{l}\text { Narrowly filamentous with few } \\
\text { septa }\end{array}$ & Filamentous with septa & $\begin{array}{l}\text { Narrowly filamentous } \\
\text { with septa }\end{array}$ & Narrowly filamentous with septa \\
\hline & Size $(\mu \mathrm{m})$ & $\begin{array}{l}(130-) 183.9-350.4(-378.2) \text { by } \\
2.1-3.3\end{array}$ & $25.6-166.3$ by $4.2-8.2$ & $225-275$ by 2 & $275-325$ by 2.5 \\
\hline
\end{tabular}

\footnotetext{
${ }^{\text {a }}$ Potato carrot agar.

${ }^{\mathrm{b}}$ The growth of A. elegans was described by Simmons (2000).
} 
associated with the families Caryophyllaceae, Solanaceae, and Pedaliaceae, respectively (Ellis and Ellis 1985; Simmons 2000, 2004). Most Alternaria spp. on species of Asteraceae belong to sect. Porri (Simmons 2007; Woudenberg et al. 2014). In this study, A. kareliniae was associated with $K$. caspia, which is also in the Asteraceae family. This further demonstrates and confirms that Alternaria sect. Dianthicola has no strong host plant family specialization or association.

The field observations and in vitro pathogenicity studies showed that $A$. kareliniae is an aggressive pathogen of $K$. caspia, capable of killing the plants within a short period following infection. Widespread mortality of Caspian Sea karelinia has been increasing in frequency with increasing rainfall in recent years, and the disease incidence appears to be increasing. Because $K$. caspia is becoming widely grown in the desert regions of the Tarim and Junggar Basins for preventing local soil erosion, the disease poses a serious threat to soil de-desertification and salt-alkalization control strategies. Studies on pathogen variation, disease progression, pathogenicity on plants in the field, and disease management should be done in the future.

\section{Acknowledgments}

This research was supported by the National Natural Science Foundation of China (numbers 31360007 and 31460008), Guangdong Key Laboratory Construction Program (Guangdong Province Key Laboratory of Microbial Signals and Disease Control), and Excellent Talents Program in Xinjiang Production and Construction Corps.

\section{Literature Cited}

Abo-Elyousr, K. A. M., Sobhy, I., Abdel-Hafez, I., and Abdel-Rahim, I. 2014. Isolation of Trichoderma and evaluation of their antagonistic potential against Alternaria porri. J. Phytopathol. 162:567-574.

Berbee, M. L., Pirseyedi, M., and Hubbard, S. 1999. Cochliobolus phylogenetics and the origin of known, highly virulent pathogens, inferred from ITS and glyceraldehyde-3-phosphate dehydrogenase gene sequences. Mycologia 91: 964-977.

Cai, L., Giraud, T., Zhang, N., Begerow, D., Cai, G. H., and Shivas, R. G. 2011. The evolution of species concepts and species recognition criteria in plant pathogenic fungi. Fungal Divers. 50:121-133.

Carbone, I., and Kohn, L. M. 1999. A method for designing primer sets for speciation studies in filamentous ascomycetes. Mycologia 91:553-556.

de Hoog, G. S., and Gerrits van den Ende, A. H. G. 1998. Molecular diagnostics of clinical strains of filamentous Basidiomycetes. Mycoses 41:183-189.

Ellis, M. B., and Ellis, J. P. 1985. Microfungi on Land Plants. An Identification Handbook. Macmillan Publishing Company, Inc., New York.

Hong, S. G., Cramer, R. A., Lawrence, C. B., and Pryor, B. M. 2005. Alt a 1 allergen homologs from Alternaria and related taxa: Analysis of phylogenetic content and secondary structure. Fungal Genet. Biol. 42:119-129.

Hyde, K. D., Chomnunti, P., Crous, P. W., Groenewald, J. Z., Damm, U., Ko Ko, T. W., Shivas, R. G., Summerell, B. A., and Tan, Y. P. 2010. A case for reinventory of Australia's plant pathogens. Persoonia 25:50-60.

Katoh, K., and Standley, D. M. 2013. MAFFT multiple sequence alignment software version 7: Improvements in performance and usability. Mol. Biol. Evol. 30:772-80

Lawrence, D. P., Gannibal, P. B., Peever, T. L., and Pryor, B. M. 2013. The sections of Alternaria: Formalizing species-group concepts. Mycologia 105:530-546.

Lawrence, D. P., Park, M. S., and Pryor, B. M. 2012. Nimbya and Embellisia revisited, with nov. comb. for Alternaria celosiae and A. perpunctulata. Mycol. Prog. 11:799-815.

Lawrence, D. P., Rotondo, F., and Gannibal, P. B. 2016. Biodiversity and taxonomy of the pleomorphic genus Alternaria. Mycol. Prog. 15:3.
Lin, R. 1999. Flora Republicae Popularis Sinicae, Vol. 75, Chinese Edition. Science Press, Beijing.

Liu, Y. J., Whelen, S., and Hall, B. D. 1999. Phylogenetic relationships among ascomycetes: Evidence from an RNA polymerase II subunit. Mol. Biol. Evol. 16:1799-1808.

Lopes, C. A., and Bioiteus, L. S. 1994. Leaf spot and stem blight of sweet potato caused by Alternaria bataticola: A new record to South America. Plant Dis. 78: 1107-1109.

Nei, M., and Kumar, S. 2000. Molecular Evolution and Phylogenetics. Oxford University Press, New York.

Pryor, B. M., and Michailides, T. J. 2002. Morphological, pathogenic, and molecular characterization of Alternaria isolates associated with Alternaria late blight of pistachio. Phytopathology 92:406-416.

Rambaut, A. 2007. FigTree, A Graphical Viewer of Phylogenetic Trees. Online publication. http://tree.bio.ed.ac.uk/software/figtree

Ronquist, F., Teslenko, M., van der Mark, P., Ayres, D. L., Darling, A., Höhna, S., Larget, B., Liu, L., Suchard, M. A., and Huelsenbeck, J. P. 2012. MrBayes 3.2: Efficient Bayesian phylogenetic inference and model choice across a large model space. Syst. Biol. 61:539-542.

Rotem, J. 1994. The Genus Alternaria: Biology, Epidemiology and Pathogenicity. American Phytopathological Society Press, St. Paul, MN

Sakoda, T., Tsukiboshi, T., and Yanagisawa, H. 2010. Leaf spot of Farfugium japonicum caused by Alternaria cinerariae intercepted at plant quarantine in Japan. Res. Bull. Plant Prot. Jpn. 46:73-78.

Silvestro, D., and Michalak, I. 2012. raxmlGUI: A graphical front-end for RAxML. Org. Divers. Evol. 12:335-337.

Simmons, E. G. 2000. Alternaria themes and variations (244-286) species on Solanaceae. Mycotaxon 75:1-115.

Simmons, E. G. 2004. Novel dematiaceous hyphomycetes. Stud. Mycol. 50: 109-118.

Simmons, E. G. 2007. Alternaria. An Identification Manual. CBS Fungal Biodiversity Centre, Utrecht, The Netherlands.

Stamatakis, A. 2014. RAxML version 8: A tool for phylogenetic analysis and postanalysis of large phylogenies. Bioinformatics 30:1312-1313.

Sung, G. H., Sung, J. M., Hywel-Jones, N. L., and Spatafora, J. W. 2007. A multigene phylogeny of Clavicipitaceae (Ascomycota, Fungi): Identification of localized incongruence using a combinational bootstrap approach. Mol. Phylogenet. Evol 44:1204-1223.

Thomma, B. P. 2003. Alternaria spp.: From general saprophyte to specific parasite. Mol. Plant Pathol. 4:225-236.

Tymon, L. S., Cummings, T. F., and Johnson, D. A. 2016. Pathogenicity and aggressiveness of three Alternaria spp. on potato foliage in the U.S. northwest. Plant Dis. 100:797-801.

Vaidya, G., Lohman, D. J., and Meier, R. 2011. SequenceMatrix: Concatenation software for the fast assembly of multi-gene datasets with character set and codon information. Cladistics 27:171-180.

Vonlanthen, B., Zhang, X. M., and Bruelheide, H. 2011. Establishment and early survival of five phreatophytes of the Taklamakan Desert. Flora 206:100-106.

Wang, L., Zhao, G., Li, M., Zhang, M., Zhang, L., Zhang, X., An, L., and Xu, S 2015. C:N:P stoichiometry and leaf traits of halophytes in an Arid Saline Environment, Northwest China. PLoS One 10:e0119935.

White, T. J., Bruns, T., Lee, S., and Taylor, J. 1990. Amplification and direct sequencing of fungal ribosomal RNA genes for phylogenetics. Pages 315-322 in: PCR Protocols: A Guide to Methods and Applications. M. A. Innis, D. H. Gelfand, J. J. Sninsky, and T. J. White, eds. Academic Press, San Diego, CA.

Woudenberg, J. H. C., Groenewald, J. Z., Binder, M., and Crous, P. W. 2013. Alternaria redefined. Stud. Mycol. 75:171-212.

Woudenberg, J. H. C., Truter, M., Groenewald, J. Z., Binder, M., and Crous, P. W. 2014. Large-spored Alternaria pathogens in section Porri disentangled. Stud. Mycol. 79:1-47.

Zhang, X., Liao, M. S., Chang, D., and Zhang, F. C. 2014. Comparative transcriptome analysis of the Asteraceae halophyte Karelinia caspica under salt stress. BMC Res. Notes 7:927. 